\title{
Rats Expressing Human Cytosolic Copper-Zinc Superoxide Dismutase Transgenes with Amyotrophic Lateral Sclerosis: Associated Mutations Develop Motor Neuron Disease
}

\author{
Makiko Nagai, ${ }^{1}$ Masashi Aoki,, ${ }^{1}$ chiro Miyoshi,, ${ }^{2}$ Masaaki Kato, ${ }^{1}$ Piera Pasinelli, ${ }^{3}$ Noriyuki Kasai, ${ }^{2}$ \\ Robert H. Brown $\mathrm{Jr}^{3}{ }^{3}$ and Yasuto Itoyama ${ }^{1}$ \\ ${ }^{1}$ Department of Neuroscience, Division of Neurology, ${ }^{2}$ Institute for Experimental Animals, Tohoku University Graduate \\ School of Medicine, Sendai 980-8574, Japan, and '3ay Neuromuscular Research Laboratory, Massachusetts General \\ Hospital, Charlestown, Massachusetts 02129
}

\begin{abstract}
Some cases of familial amyotrophic lateral sclerosis (ALS) are caused by mutations in the gene encoding cytosolic, copperzinc superoxide dismutase (SOD1). We report here that rats that express a human SOD1 transgene with two different ALSassociated mutations (G93A and H46R) develop striking motor neuron degeneration and paralysis. As in the human disease and transgenic ALS mice, pathological analysis demonstrates selective loss of motor neurons in the spinal cords of these transgenic rats. In spinal cord tissues, this is accompanied by activation of apoptotic genes known to be activated by mutant SOD1 protein in vitro and in vivo. These animals provide addi-
\end{abstract}

Amyotrophic lateral sclerosis (ALS) is a fatal neurodegenerative disease caused by selective death of motor neurons (Brownell et al., 1970; Brown, 1995, Cleveland, 1999). Approximately 10\% of cases of ALS are inherited, usually as an autosomal dominant trait (Mulder et al., 1986). In 25\% of familial cases, the disease is caused by mutations in the gene encoding cytosolic copper-zinc superoxide dismutase (SOD1) (Rosen et al., 1993). Nearly 100 different mutations in the SOD1 gene have been identified in familial ALS. Why the mutations cause motor neuron degeneration is not fully elucidated. That the primary abnormality is not loss of SOD1 dismutation activity is supported by the observation that many mutant forms of SOD1 retain nearly normal SOD1 activity. Moreover, mice with targeted inactivation of the SOD1 gene do not develop motor neuron disease (Reaume et al., 1996). Perhaps most compelling is the observation that mice expressing human SOD1 transgenes with three different ALS-associated mutations develop progressive motor neuron disease despite elevated (Gurney et al., 1994; Ripps et al., 1995; Wong et al., 1995)

\footnotetext{
Received June 15, 2001; revised Sept. 4, 2001; accepted Sept. 14, 2001.

This work was supported by a grant on Specific Diseases (Itoyama) from the Ministry of Health and Welfare, Japan. Research funding was also provided to I.M. and N.K. by the Ministry of Education, Culture, Sports, Science and Technology, Japan (Grants 11680816, 12794020), and to R.H.B. and P.P. by the National Institutes of Health (Grants PO1NS31248, PO1NS37912), the Myrtle May MacClellan ALS Research Foundation, the Pierre L. de Bourgknecht ALS Research Foundation, the Amyotrophic Lateral Sclerosis Association, the Muscular Dystrophy Association, Project ALS, the Angel Fund for ALS Research, and the Al Athel Foundation for ALS Research. We thank Drs. M. Ohira and A. Nakagawara for cloning the PAC clone used in this study, and Drs. T. Kitamoto and K. Abe for helpful discussions. We also thank R. Kamii and Y. Onodara for technical assistance and Dr. S. Kure for the measurement of amino acid levels in the CSF.

Correspondence should be addressed to Dr. Masashi Aoki, Department of Neuroscience, Division of Neurology, Tohoku University Graduate School of Medicine, 1-1 Seiryo-machi, Sendai 980-8574, Japan. E-mail: aokim@mail.cc.tohoku.ac.jp. Copyright (C) 2001 Society for Neuroscience $0270-6474 / 01 / 219246-09 \$ 15.00 / 0$
}

tional support for the proposition that motor neuron death in SOD1-related ALS reflects one or more acquired, neurotoxic properties of the mutant SOD1 protein. The larger size of this rat model as compared with the ALS mice will facilitate studies involving manipulations of spinal fluid (implantation of intrathecal catheters for chronic therapeutic studies; CSF sampling) and spinal cord (e.g., direct administration of viral- and cellmediated therapies).

Key words: familial amyotrophic lateral sclerosis; copper-zinc SOD; SOD1; transgenic rats; glutamate; caspase or unchanged (Bruijn et al., 1997) levels of SOD1 activity. The phenotype of these transgenic ALS mice strikingly recapitulates human ALS. The primary pathological finding is neuronal degeneration that predominantly affects motor neurons. In addition, from an early age, the spinal cords of these mice reveal activation of non-neuronal cell types, including astroglial and microglial cells (Hall et al., 1998). These transgenic ALS mice have importantly advanced our understanding of the pathogenesis of neuronal cell death induced by mutant SOD1 protein and have facilitated therapeutic trials (Gurney et al., 1996). However, some types of experimental manipulations have been difficult in the ALS mice because of their innate size limitations. It has been almost impossible, for example, to analyze CSF from the ALS mice, even at single time points. It has also been very difficult to use therapies that involve administration of compounds into the cerebrospinal fluid. There is only a single report of pumpmediated delivery of therapies to the cerebrospinal fluid of the ALS mice, and that approach was intraventricular rather than intrathecal ( $\mathrm{Li}$ et al., 2000); it is likely that intrathecal administration will produce significantly better therapeutic levels of compounds at the spinal cord level than will the intraventricular approach (Gurney et al., 2000). It has also been difficult to obtain sufficient tissue to perform extensive biochemical analyses, such as investigations of post-transcriptional modifications of proteins such as SOD1 itself during disease progression. For these reasons, we have developed a rat model of ALS by expressing a human SOD1 transgene with two ALS-associated mutations, H46R and G93A. Like the murine counterpart, this rat transgenic ALS model reproduces the major phenotypic features of human ALS. Because the CSF volume of a rat is 10 - to 20 -fold greater than that of a mouse, the ALS rats allow ready CSF access and evaluation. Moreover, these rats also allow routine implantation 
of infusion pumps for intrathecal drug delivery at any desired level in the spinal cord.

\section{MATERIALS AND METHODS}

Construction of transgenic mice expressing mutant human SOD1. We isolated a P1-derived artificial clone (dJ1001A14) containing the full genomic human SOD1 gene; this was identified by screening a human genomic PAC library (Ioannou et al., 1994) using PCR with primer pairs specific to the human SOD1 gene. From this we cloned an $11.5 \mathrm{~kb}$ EcoRI-BamHI fragment that contained the entire coding sequence and promoter region of the human SOD1 gene (Levanon et al., 1985; ElroyStein et al., 1986). The H46R and G93A mutations were engineered into this fragment by site-directed mutagenesis (Mutan-express Km, Takara, Otsu, Japan). For the H46R mutation, a NdeI-XbaI fragment of the human SOD1 gene involving the second exon was subcloned into the pKF18k vector (Takara), which had a mutation that impaired the kanamycin $(\mathrm{Km})$ resistance gene. For the G93A mutation, a XbaI-Pst I fragment encompassing the exon 4 was subcloned into the pKF18k vector. Both the mutagenic primer and selection primer, which restored $\mathrm{Km}$ resistance, hybridized to the vector and were incorporated during replication. Resulting potential $\mathrm{Km}$ resistant clones were sequenced (oligonucleotide-directed dual amber method) (Hashimoto-Gotoh et al., 1995) to verify the presence of either of the introduced mutations, H46R or G93A.

Female Sprague Dawley rats (Japan SLC, Inc., Hamamatsu, Japan) were superovulated by gonadotropin from pregnant mare serum and hCG (Puberogen, Sankyo Yeil Yakuhin Co. Ltd., Tokyo, Japan) injections. Their fertilized eggs at pronuclear stages were obtained $32 \mathrm{hr}$ after hCG injection. Microinjections of a linear $11.5 \mathrm{~kb}$ EcoRI-BamHI fragment containing the H46R and G93A mutations were performed with the aid of a pair of micromanipulators (Narishige, Tokyo, Japan) and interference-contrast optics (Nikon, Tokyo, Japan). The treated embryos were cultured for $12-15 \mathrm{hr}$ in modified Krebs'-Ringer's bicarbonate buffer at $37^{\circ} \mathrm{C}$ and were transferred to oviducts of pseudopregnant females (Hochi et al., 1990).

DNA of newborn rats was extracted from their tails, and PCR amplification (forward primer: 5'-TTGGGAGGAGGTAGTGATTA; reverse primer: $5^{\prime}$-AGCTAGCAGGATAACAGATGA; $94^{\circ} \mathrm{C}$ for $30 \mathrm{sec} ; 55^{\circ} \mathrm{C}$ for $30 \mathrm{sec} ; 72^{\circ} \mathrm{C}$ for $30 \mathrm{sec} ; 30 \mathrm{cycles}$ ) and Southern blotting were used to detect the exogenous human SOD1 transgene DNA. The human SOD1 cDNA was used as a probe for the Southern blotting. Founder rats were mated with Sprague Dawley rats.

All rats were handled according to approved animal protocols in our institution.

SDS-PAGE and immunoblotting. For SOD1 immunodetection, total protein extracts of various tissue from transgenic and control rats (nontransgenic littermates) were homogenized in buffer containing $25 \mathrm{~mm}$ sodium phosphate, $\mathrm{pH}$ 7.2, $1 \mathrm{~mm}$ EDTA, $1 \mu \mathrm{g} / \mathrm{ml}$ pepstatin A, and $1 \mathrm{~mm}$ PMSF. After determining the protein concentration using a bicinchoninic acid protein assay (Pierce Chemical Company, Rockford, IL), $4 \mu \mathrm{g}$ of total protein was loaded onto a $15 \%$ polyacrylamide gel, electrophoresed, and transferred onto filters. Endogenous rat SOD1 and mutant human SOD1 were detected using a sheep anti-human SOD1 antibody (Calbiochem, San Diego, CA) followed by enhanced chemiluminescence detection (Amersham, Buckinghamshire, UK). Signals were quantified using a phosphorimager with "Luminous Imager" software analysis (Aisin Cosmo, Kariya, Japan).

Measurement of SOD1 activity. The spinal cords of the transgenic and control rats were homogenized in buffer containing $20 \mathrm{~mm}$ Tris- $\mathrm{Cl}, \mathrm{pH}$ 7.2, 1 mM EDTA, and 1\% Triton X-100. These were then centrifuged at $10,000 \times g$ for $5 \mathrm{~min}$. The resulting supernatants were electrophoresed on a $7.5 \%$ polyacrylamide gel at $20 \mu \mathrm{g}$ total protein for each lane. SOD1 activity was determined by the ability of SOD1 to inhibit the superoxide anion-induced conversion of nitro-tetrazolium blue to formazan (Beauchamp and Fridovich, 1971). These SOD1 activity gels were quantified using human erythrocyte SOD1 (Sigma, St. Louis, MO) as standards with Luminous Imager software analysis (see above).

Estimated motor neuron counts. The estimated motor neuron counts were performed on hematoxylin + eosin-stained $10 \mu \mathrm{m}$ sections at the L3 level. Cells were selected as motor neurons if they were $>25 \mu \mathrm{m}$ in diameter, multipolar with neuronal morphology, and located in the anterior horn of the spinal cord. For each strain, three sections were counted bilaterally from each of three different rats at each point in time. The resulting data (from 6 anterior quadrants at each point in time from each rat, or a total of 18 anterior quadrants) were averaged to provide an estimated number of motor neurons per quadrant. Although this method does not provide an absolute motor neuron count by the standard of present stereological counting procedures, it does provide a useful estimate that allowed comparison of the size of the motor neuron pool in the H46R-4 and G93A-39 as compared with the control littermate rats.

Movement activity. Movement activity of transgenic rats and control littermates was analyzed using an Automex II locomotor activity meter (Columbus Instruments, Columbus, $\mathrm{OH}$ ); this counts the number of times the rat's feet strike pressure sensors at various points in the test chamber during a $24 \mathrm{hr}$ period (Yamada et al., 1986).

Quantitation of caspase-1 and -3 activities. Spinal cords from rats were homogenized in buffer containing $10 \mathrm{~mm}$ Tris- $\mathrm{HCl}, 10 \mathrm{~mm} \mathrm{NaH}_{2} \mathrm{PO}_{4} /$ $\mathrm{NaHPO}_{4}$, pH 7.5, $130 \mathrm{~mm} \mathrm{NaCl}, 1 \%$ Triton X-100, and $10 \mathrm{~mm} \mathrm{NaPPi}$ in the presence of a protease inhibitor mixture. After centrifugation at $20,000 \times g$ for $30 \mathrm{~min}$, protein concentration was determined by the Bradford assay using bovine serum albumin as a standard. Equal amounts of lysates were then incubated with $200 \mu \mathrm{l}$ of HEPES buffer in the presence of either $N$-acetyl-Tyr-Val-Ala-Asp-AMC 7-amino-4-methylcoumarin (AMC) or $N$-acetyl-Asp-Glu-Val-Asp-AMC (PharMingen, San Diego, CA) to measure caspase-1 and -3 , respectively. At the end of this incubation, fluorescence of the free AMC fluorophore was measured using a Fluo-star BMG fluorimeter (BMG Lab Technologies, Chapel Hill, NC) at an excitation wavelength of $380 \mathrm{~nm}$ and an emission wavelength of $420 \mathrm{~nm}$.

CSF study for amino acids. Rats were anesthetized using diethyl ether and $1 \%$ halothane in a mixture of $30 \%$ oxygen and $70 \%$ nitrous oxide. A 27 gauge needle was introduced into the cerebellomedullary cistern with a micromanipulator, and $\sim 100 \mu \mathrm{l}$ of CSF was collected. CSF was collected from five G93A-39 transgenic rats at 2 months of age and five at end stage (4.5 month old); similar samples were obtained from three nontransgenic littermates (4.5 month old). An aliquot of each CSF sample was centrifuged, cleared of proteins by precipitation with $10 \%$ trichloroacetic acid, neutralized, diluted, and filtered. Amino acids (aspartate, asparagine, glutamate, glutamine, and glycine) were measured using HPLC with electrochemical detection with CoulArray Medical System (Coulochem II, Model 5200, Esa, Inc., Chelmsford, MA). Statistical analysis was analyzed by Mann-Whitney $U$ test.

Histopathological and immunohistochemical analyses. The rats anesthetized with diethyl ether were killed by transcardiac perfusion with $0.9 \%$ sodium chloride, followed by $4 \%$ paraformaldehyde in $0.1 \%$ PBS, $\mathrm{pH} 7.4$. The brains and spinal cords were removed, post-fixed the same solution, embedded in paraffin, and sectioned $(10 \mu \mathrm{m})$. In all experiments, sections were deparaffinized before staining with hematoxylin and eosin or immunostaining. Immunohistochemistry was performed using antibodies recognizing human SOD1 (Calbiochem), ubiquitin (Dako, Carpinteria, CA), glial fibrillary acidic protein (GFAP) (Dako), and phosphorylated neurofilaments (SMI31, Sternberger Monoclonal Inc., Lutherville, MD). For immunostaining, sections were quenched for $30 \mathrm{~min}$ in methanol and $0.3 \%$ hydrogen peroxide, rinsed in PBS, and incubated overnight in the primary antibody. Immunoreactivity was visualized with diaminobenzidine and sections were counterstained with hematoxylin.

\section{RESULTS}

\section{Generation of transgenic rats with mutant SOD1}

We elected to make transgenic rats with two mutations in the SOD1 genes: histidine 46 to arginine (H46R) and glycine 93 to alanine (G93A). These were selected for two reasons. First, these mutations have distinctly different consequences for SOD1 activity. Although the SOD $1^{\mathrm{H} 46 \mathrm{R}}$ mutant involves one of the residues binding catalytic copper at the active site and consequently has impaired SOD dismutation activity, dismutation activity is retained in the SOD1 ${ }^{\text {G93A }}$ mutant (Borchelt et al., 1994). Second, in patients we have encountered with these mutations, the phenotypes are quite different. For H46R patients, progression is extremely slow (Aoki et al., 1993), whereas patients with the SOD1 ${ }^{\text {G93A }}$ mutation demonstrate a more fulminant classic clinical course (Cudkowicz et al., 1997). Moreover, the transgenic ALS mouse with this G93A mutation has been widely distributed and studied throughout the world.

To generate the transgenic rats with the H46R and G93A mutations, we first obtained human genomic PAC clones encom- 


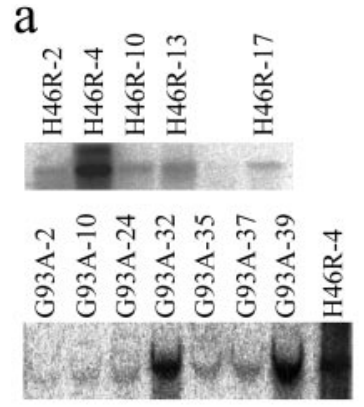

$\mathrm{C}$
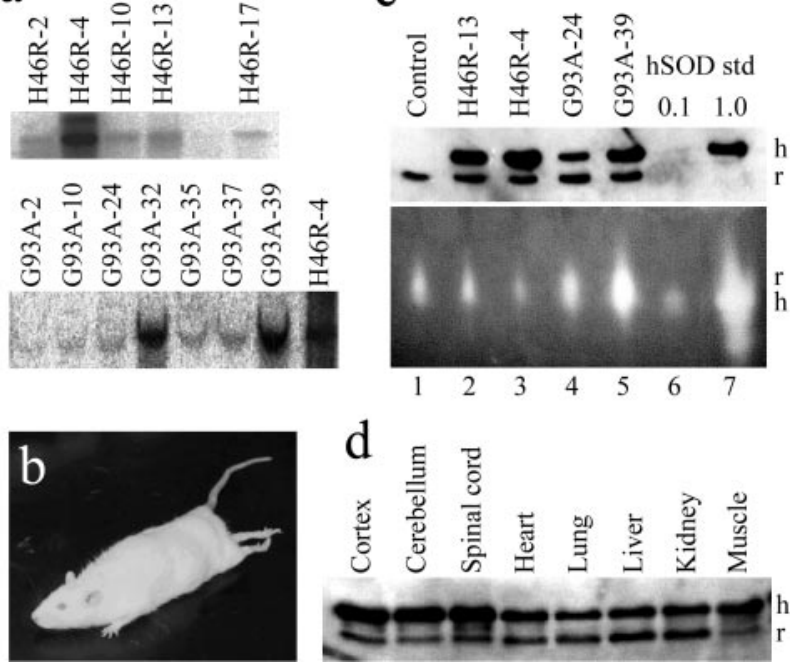

Figure 1. Analysis of human SOD1 transgene (H46R or G93A) copy number, protein expression, and SOD1 activity. $a$, Southern analysis of the human SOD1 gene in transgenic rats as determined by tail DNA blots. Five transgenic lines were established with the H46R mutation (top row), and seven transgenic lines were established with the G93A mutation (bottom row). The H46R-4 blot is shown in each row to allow comparison of the H46R and G93A results. $b$, An affected transgenic rat from the H46R-4 line demonstrates hindlimb weakness and abnormal posturing with segmental spasticity of the tail. $c$, Top panel, Quantitative immunoblotting of $4 \mu \mathrm{g}$ of total protein extracts of spinal cord from nontransgenic littermate control, H46R lines (H46R-4, H46R-13), and G93A lines (G93A-24, G93A-39) using sheep polyclonal antibodies that recognize a common epitope shared between human $(h)$ and rat $(r)$ SOD1. Two 10-fold dilutions of purified human erythrocyte SOD1 (0.1, 1.0 U) were immunoblotted in parallel to provide standards for quantitation. Bottom panel, SOD1 enzymatic activity in spinal cord extracts ( $20 \mu \mathrm{g}$ of protein) from the same nontransgenic littermate control or transgenic rats determined on native gels. Note that the electrophoretic migration of rat SOD1 $(r)$ differs from that of human erythrocyte SOD1 $(h) . d$, Total protein $(4$ $\mu \mathrm{g})$ from various tissues from 2-month-old transgenic H46R-4 rats was immunoblotted with the same sheep polyclonal antibody as in $c$, recognizing human and rat SOD1.

passing the entire human SOD1 gene; we then subcloned this gene within an $11.5 \mathrm{~kb}$ EcoRI-BamHI fragment. Site-directed mutagenesis was used to generate clones with either the H46R or G93A mutation. The mutated $11.5 \mathrm{~kb}$ EcoRI-BamHI fragments were microinjected into fertilized eggs from Sprague Dawley rats. Twenty-five potential transgenic H46R pups were obtained. From these, five founders with the H46R mutant transgene were identified using the PCR and Southern blotting (Fig. 1a, top panel). Fifty-two potential transgenic G93A pups were obtained. From these, seven founders with the G93A mutant transgene were identified (Fig. 1a, bottom panel). Levels of accumulated mutant SOD1 were measured for almost all founders by quantitative protein immunoblotting of spinal cord extracts using antibody against a peptide sequence that is identical in human and rat SOD1 (Table 1). Two lines were established for each mutation from the founders expressing the highest levels of the mutant SOD1 (Table 1).

\section{Expression levels of the mutant SOD1 protein and determination of SOD1 activities}

To determine the levels of the human mutant SOD1 protein that accumulated in each of the transgenic lines, spinal cord extracts were immunoblotted. The ratios of human mutant to rat endogenous SOD1 were determined using an anti-human polyclonal antibody against a peptide sequence identical in human and rat SOD1 (Calbiochem). The level of human mutant SOD1 protein in the lines H46R-4, H46R-13, G93A-24, and G93A-39 were 6.0, 2.5, 0.8, and 2.5 times the level of endogenous rat SOD1 (Fig. $1 c$, top panel, Table 1). Extracts of various tissues of the line H46-R4, including cortex, cerebellum, spinal cord, heart, kidney, liver, lung, and skeletal muscle, were immunoblotted with the same anti-human SOD1 antibody. Although there was clear immunoreactivity for the mutant human SOD1 in all of these tissues, the highest levels of human relative to rat endogenous SOD1 were evident in the CNS samples (cortex, cerebellum, spinal cord) (Fig. 1d).

To determine the level of SOD1 activity, spinal cord extracts of transgenic rats as well as controls were electrophoresed in native gels. SOD1 activity was quantified in situ on the gels using a well established assay in which dismutation of superoxide anion by SOD1 inhibits the conversion by superoxide anion of nitro-blue tetrazolium to formazan, resulting in a formazan-free clear zone in an otherwise blue gel (Beauchamp and Fridovich, 1971). In two lines with G93A mutations, the SOD1 activities were increased to 200 and $300 \%$ of the control level, respectively (Fig. 1c, bottom panel); these total activities reflect the combined contributions of the endogenous rat and the transgenic human SOD1. In the two lines with the H46R mutation, the gel assay loaded at the same concentration of protein per lane revealed total spinal cord SOD1 enzyme activities that were $\sim 20$ and $40 \%$ of the control level (Fig. 1c, bottom panel).

\section{The clinical course of transgenic rats}

The transgenic rats expressing the higher levels of each human SOD1 mutant (lines G93A-39 and H46R-4) developed motor neuron disease (Fig. 1b, Table 1). The first sign of pathology in these higher expressing lines was a diminution in spontaneous walking activity in the cage, as measured by $24 \mathrm{hr}$ automated monitoring (Fig. 2a) (Automex II). This was evident by $110 \mathrm{~d}$ for the G93A-39 line and by $140 \mathrm{~d}$ for the H46R-4 line. Clinically apparent weakness, denoted by dragging of one hindlimb without limb tremor, was evident somewhat later. The mean age of onset of this clinical weakness for the G93A-39 line was $122.9 \pm 14.1 \mathrm{~d}$ $(n=14)$; for the H46R-4 line, the age of onset was $144.7 \pm 6.4 \mathrm{~d}$ $(n=18)$ (Table 1). Simultaneously with the onset of clinical weakness, the affected rats showed prominent weight loss (Fig. $2 b)$. Although the initial clinical manifestation of weakness was unilateral leg paralysis, this progressed and became bilateral in both lines of rats. In the early stages of the illness, another distinctive abnormality was increased tone in the tail musculature, resulting in an elevated, segmentally spastic tail posture. As the disease progressed, the rats exhibited marked muscle wasting in the hindlimbs and typically dragged themselves around the cage using the forelimbs. Thereafter, the forelimbs also became weak, in association with further weight loss. At end stage, the affected rats could not drink water and died. The mean durations of the clinical expression of the disease in the G93A-39 and H46R-4 lines were $8.3 \pm 0.7 \mathrm{~d}(n=14)$ and $24.2 \pm 2.9 \mathrm{~d}(n=18)$, respectively (Table 1 ). By contrast, the lines that expressed lower levels of the mutant SOD1 (H46R-13 and G93A-24) did not shown any clinical phenotype at 12 months of age (Table 1). The onset and survival data for the G93A-39 and H46R-4 rats are summarized in the Kaplan-Meier survival curves (Fleming and Lin, 2000) in Figure 2, $c$ and $d$.

We have estimated the numbers of motor neurons in each anterior horn of the control and transgenic rats as a function of 


\begin{tabular}{|c|c|c|c|c|c|}
\hline Line & $\begin{array}{l}\text { Copy } \\
\text { number }\end{array}$ & $\begin{array}{l}\text { Relative SOD1 } \\
\text { protein levels } \\
\text { (spinal cord) (human/rat) }\end{array}$ & $\begin{array}{l}\text { SOD activity } \\
\text { relative to control } \\
\text { (spinal cord) }\end{array}$ & $\begin{array}{l}\text { Age of } \\
\text { onset (days) }\end{array}$ & $\begin{array}{l}\text { Duration } \\
\text { (days) }\end{array}$ \\
\hline H46R-2 & 2 & 1.6 & ND & None & None \\
\hline H46R-4 & 25 & 6.0 & 0.21 & $144.7 \pm 6.4$ & $24.2 \pm 2.9$ \\
\hline H46R-10 & 3 & 2.6 & ND & None & None \\
\hline H46R-13 & 5 & 3.0 & 0.4 & None & None \\
\hline H46R-17 & 2 & 0.8 & ND & None & None \\
\hline G93A-2 & 1 & 0 & ND & None & None \\
\hline G93A-10 & 1 & 0.8 & ND & None & None \\
\hline G93A-24 & 3 & 0.8 & 2 & None & None \\
\hline G93A-32 & 10 & 2.0 & ND & None & None \\
\hline G93A-35 & 2 & ND & ND & None & None \\
\hline G93A-37 & 2 & ND & ND & None & None \\
\hline G93A-39 & 10 & 2.5 & 3 & $122.9 \pm 14.1$ & $8.3 \pm 0.7$ \\
\hline
\end{tabular}

ND, Not determined.

age. As indicated in Table 2, for both the H46R-4 and G93A-39 lines, the estimated number declines abruptly in parallel with the development of clinical paralysis. As predicted by the clinical course, the decline in estimated counts begins earlier and progresses more rapidly in the G93A-39 line. In both lines, the drop-off in estimated motor neuron numbers precedes the onset of clinical weakness.

\section{a}

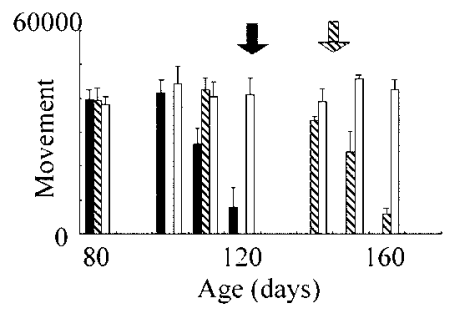

b

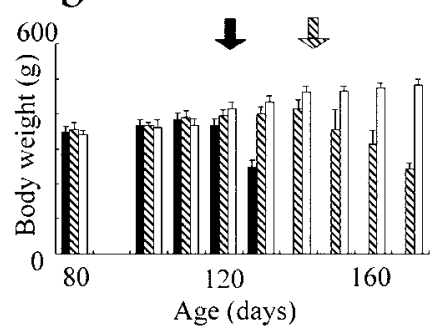

c

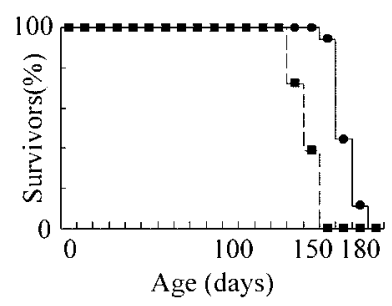

d

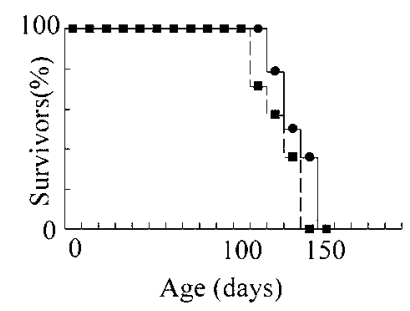

Figure 2. Phenotypic markers of disease progression in the transgenic (H46R-4, G93A-39) ALS rats. $a$, Spontaneous walking movements decreased by 110 and $150 \mathrm{~d}$ for the G93A-39 and H46R-4 rats, respectively, as measured using an Automap II apparatus. $b$, Body weights for these two lines of rats began to fall at approximately the same age as onset of clinically apparent weakness $(\sim 123 \mathrm{~d}$ for the G93A-39 line and $\sim 145 \mathrm{~d}$ for the H46R-4 line). $c$, Kaplan-Meier curves illustrating the ages of onset (mean $145 \mathrm{~d}$ ) and death (mean $169 \mathrm{~d}$ ) for the H46R-4 rats. $d$, KaplanMeier curves illustrating the ages of onset (mean $123 \mathrm{~d}$ ) and death (mean $131 \mathrm{~d}$ ) for the G93A-39 rats. In $a$ and $b$, solid bars $=$ G93A-39 transgenic rats, hatched bars $=\mathrm{H} 46 \mathrm{R}-4$ transgenic rats, and open bars = nontransgenic littermate control rats. The ages of the first appearance of clinical weakness are indicated by the solid (G93A-39) and hatched (H46R-4) arrows. In $c$ and $d$, the dashed lines with black square data points designate the onset curves (percentage without weakness), whereas the solid lines with black dots designate the survival curves (percentage surviving).

\section{Histopathological studies in the nervous system}

To evaluate the distribution of abnormalities in the nervous system, we examined a total of 24 rats of various ages from the affected lines and nontransgenic littermates. In general, both the G93A and H46R transgenic rats exhibited neuropathological abnormalities associated with degeneration of motor neurons in the ventral horns of the spinal cord as well as motor neurons in the brain stem (Fig. 3b,c). Both also showed evidence of proliferation of small nonneuronal cells with morphological characteristics of astroglia (Fig. 3e,f) and microglia. For the rats in the G93A-39 line, at $90 \mathrm{~d}$ of age, the numbers of large, multipolar neurons in the anterior horn (motor neurons) were decreased as compared with controls, whereas the numbers of hypertrophic astrocytes were increased (Fig. $3 e, f$ ). Moreover, ubiquitination of dendrites and axons of motor neurons was readily evident in the ventral horn (Table 2). These changes were not evident in the nontransgenic littermates.

The pathology in the G93A rats was distinguished by an abundance of vacuoles in the neuropil in the ventral horn (Fig. 3b). These were particularly abundant in the ventral horn neuropil (Fig. 3b) but were also evident in dendrites and axons (Fig. 3i). Vacuoles were also detected in the perikarya of motor neurons (Fig. $3 g$ ). Dendritic and axonal vacuoles were also definitively visualized by immunostaining with an antibody recognizing phosphorylated neurofilament heavy subunits (Fig. 3j).

Such vacuolar features were less apparent in the affected H46R rats (Fig. 3c). However, by contrast with the G93A rats, the H46R rats had an abundance of aggregates of various descriptions, particularly late in the course of the disease. In the H46R-4 line, rats that were clinically presymptomatic at $90 \mathrm{~d}$ of age demonstrated increased numbers of reactive astrocytes in the ventral horn. By 120 d, when still presymptomatic, the anterior horns of the same rats revealed decreased numbers of large, multipolar neuronal cells with a further increase in the numbers of astrocytes and microglia. Also at $120 \mathrm{~d}$, ubiquitination of the dendrites and axons was evident in the ventral horn of the lumbar spinal cord (Table 2). By $145 \mathrm{~d}$, when clinical weakness became apparent in the H46R-4 line, there was marked loss of large, multipolar neurons (Fig. $3 c$ ). At that time, numerous hypertrophic astrocytes and microglia were evident, as were sites of swelling in axons in the ventral horn (Fig. 3c). By contrast with the findings in 
Table 2. Progressive pathology in spinal cord of transgenic rats

\begin{tabular}{|c|c|c|c|c|c|c|c|}
\hline \multirow[b]{2}{*}{ Age (days) } & \multicolumn{4}{|l|}{ H46R-4 } & \multicolumn{3}{|l|}{ G93A-39 } \\
\hline & 90 & 120 & 150 & 170 & 90 & 120 & 130 \\
\hline Reactive astrogliosis & $(+)$ & $(+)$ & $(++)$ & $(+++)$ & $(+)$ & $(++)$ & $(+++)$ \\
\hline Motor neuron loss & $(-)$ & $(+)$ & $(++)$ & $(+++)$ & $(+)$ & $(++)$ & $(+++)$ \\
\hline Ubiquitination & $(-)$ & $(+)$ & $(++)$ & $(+++)$ & $(+)$ & $(++)$ & $(+++)$ \\
\hline Hyaline inclusion & $(-)$ & $(-)$ & $(+)$ & $(++)$ & $(-)$ & $(+)$ & $(+)$ \\
\hline Vacuolation & $(-)$ & $(-)$ & $(-)$ & $( \pm)$ & $(-)$ & $(+)$ & $(++)$ \\
\hline $\begin{array}{l}\text { Estimated motor neur } \\
\text { Control } 16.4 \pm 1.7\end{array}$ & $160+20$ & $131+21$ & $97+22$ & $54+12$ & $123+14$ & 10 & $42+00$ \\
\hline
\end{tabular}

the G93A rats, in the dendrites and neurons of the H46R-4 rats, the vacuolar change was not remarkable. However, by $145 \mathrm{~d}$, the H46R-4 rats showed multiple, readily apparent inclusions. Many inclusions were characterized by a dense core and clear peripheral halo, strongly resembling Lewy body-like hyaline inclusions that have been seen both in spinal cords of human ALS patients and in the G85R transgenic mice. These were detected in the neuropil, motor neurons, and astrocytes (Fig. $3 h$ ). In the anterior horns of the H46R-4 rats, axons were often thick, tortuous, and partially eosinophillic by hematoxylin and eosin staining (Fig. $3 k$ ). Those swollen ventral axons were immunostained with antiphosphorylated neurofilament antibody (SMI31) (Fig. 3l), whereas few anterior horn motor neurons were immunostained with this antibody. Many of the striking inclusion bodies in the neuropil, motor neurons (Fig. $4 a-d$ ), and astrocytes (Fig. $4 e-h$ ) of the H46R-4 rats immunostained positively for either ubiquitin or human SOD1, or both. Some Lewy body-like inclusions in neuropil were immunoreactive for SMI31 (data not shown).

Despite the fact that the H46R and G93A transgenes were expressed at high level in the cerebellum and cortex, no cerebellar or cortical pathology was evident in the H46R-4 and G93A-39 lines.

\section{Amino acid levels in CSF}

Several lines of investigation have favored the hypothesis that elevated synaptic levels of one or more excitatory neurotransmitters accelerate motor neuron death in ALS (Shaw and Ince, 1997). One approach to assessing the status of excitatory transmitters in the CNS has been to evaluate levels in CSF. For example, it has been reported that CSF levels of the amino acid glutamate are elevated in human ALS (Rothstein et al., 1990), although this result has been disputed (Perry et al., 1990). The size of these transgene ALS rats allows serial assays of CSF. We therefore obtained CSF from five of the 2-month-old and five of the end stage transgenic rats (line G93A-39) as well as three nontransgenic control littermates and recorded the levels of five amino acids that are implicated in the control of excitatory tone: glutamine, glutamate, aspartate, asparagines, and glycine. Significant abnormalities were detected only for glutamine, the concentration of which in CSF from end stage transgenic rats (4.5 month old) was elevated as compared with the nontransgenic littermates (Fig. 5a). By contrast, glutamine levels of 2-month-old transgenic rats did not differ significantly from normal littermate controls. There were no significant differences in concentrations of glutamate, aspartate, asparagine or glycine in CSF among 2 month-old and end stage transgenic rats and control littermates (Fig. $5 b$ ).

\section{Assays for caspase-1 and caspase-3 activities}

Recent studies of transgenic ALS mice in vivo and cell lines expressing mutant SOD1 protein in vitro indicate that one feature of the cell death process initiated by this protein is sequential activation of caspase-1 and then caspase-3 (Pasinelli et al., 1998, 2000; Li et al., 2000; Vukosavic et al., 2000). We have therefore assayed for activation of these caspases using the H46R-4 line. A fluorogenic assay for activity of these caspases documented that spinal cord caspase- 1 activity is elevated compared with nontransgenic littermates early in the course of the disease; this subsides to normal levels by the late stages of the disease (Fig. 6a). By contrast, caspase- 3 activity is normal at 2 months of age but rises significantly above that of the age-matched control littermates as the disease progresses (Fig. $6 b$ ). In the cerebellum, the activity of caspase- 1 and -3 does not differ from that of the control littermates (data not shown), indicating that caspase activation occurs only in regions affected by neurodegeneration in ALS. In accordance with the observation that caspase- 1 activity is elevated early in the disease, spinal cord levels of mature interleukin- $1 \beta$ (IL-1 $\beta$ ), a specific marker of caspase-1 activation, were approximately twofold higher in asymptomatic ALS rats when compared with age-matched littermate controls. In end stage transgenic ALS rats, the levels mature of IL- $1 \beta$ were comparable with those of nontransgenic controls, confirming that caspase- 1 activity is reduced in the late stage of the disease (data not shown).

\section{DISCUSSION}

We have established lines of rats that express transgenes for mutant SOD1 protein with two different ALS-associated mutations, H46R and G93A. Rats with the highest transgene copy numbers and levels of expression of the mutant protein develop a paralytic disorder characterized by fulminant motor neuron death accompanied by astrogliosis and microgliosis. Particularly striking in the G93A line is vacuolar pathology in the neuropil, whereas the H46R line shows distinctive protein aggregates with features of Lewy bodies in both neurons and astrocytes.

Why mutant SOD1 proteins are toxic to motor neurons remains unclear, despite numerous studies. Two observations are pertinent. First, the propensity to develop motor neuron pathology is proportional to the level of mutant SOD1 protein. For both mutations, only the lines with the highest copy number and highest levels of mutant transgenic protein expression developed pathology. Second, the nature of the pathology is dependent on the properties of the mutant SOD1 protein. The G93A protein retains a high level of dismutation activity and develops motor neuron degeneration with distinctive vacuolar pathology. This 

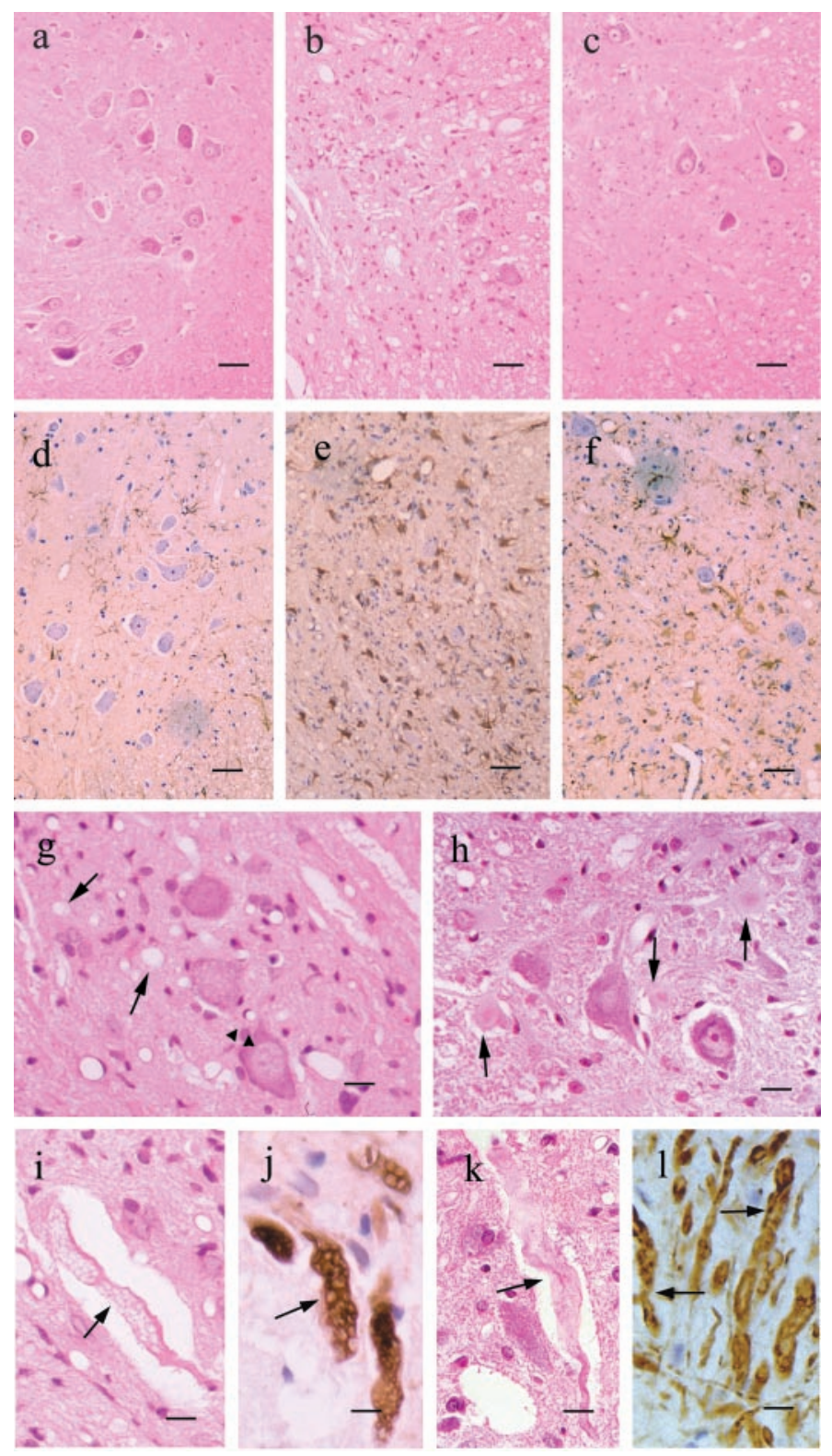

Figure 3. Major histopathological findings in the G93A-39 and H46R-4 transgenic rats. $a-f$, Ventral horns of the lumbar spinal cord from a 6-month-old normal littermate $(a, d)$, a G93A-39 transgenic rat at 4.5 months $(b, e)$, and an H46R-4 transgenic rat at 6.0 months $(c, f)$. Sections were stained with hematoxylin and eosin $(a-c)$ and immunostained using GFAP $(d-f) . g, h$, Higher magnification views of the neuropil in the ventral horn of the lumbar spinal cord in G93A-39 $(g)$ and H46R-4 $(h)$ transgenic rats. $g$, Conspicuous vacuoles in the neuropil (arrows) and perikarya of motor neuron (arrowheads) are indicated in the G93A-39 transgenic rat section. $h$, Lewy body-like inclusions are readily apparent (arrows) in the neuropil of the H46R-4 transgenic rat. $i$, Axonal swelling and vacuolation in the G93A-39 transgenic rat. $j$, Phosphorylated neurofilament is identified using antibody SMI-31 in the G93A-39 rats. $k$, Swollen and tortuous ventral axon in H46R-4. l, Phosphorylated neurofilaments are also identified with antibody SMI-31 in the H46R-4 rats. In $i-l$, the arrows designate axons. Scale bars: $a-f, 50 \mu \mathrm{m} ; g, h, 20 \mu \mathrm{m} ; i-l, 10 \mu \mathrm{m}$.

observation has been made in previous studies of both G93A and G37R ALS mice (Gurney et al., 1994; Wong et al., 1995). Moreover, it was reported recently that high levels of wild-type SOD1 in mice also produces vacuolar pathology with some motor neuron loss (Jaarsma et al., 2000). By contrast with the G93A-39 line, the H46R-4 line expresses the mutant protein at high levels but does not have elevated dismutation activity. This is almost certainly a consequence of fact that histidine 46 is a ligand for binding copper in the normal SOD1 protein (Fridovich, 1986; Parge et al., 1992). The H46R-4 protein nonetheless produces motor neuron pathology characterized not by vacuolar degeneration but by protein deposition and aggregation. This is reminiscent of the pathological findings in the G85R transgenic mice (Bruijn et al., 1997). Similar aggregative pathology has been described in human ALS (Hirano et al., 1967; Hirano, 1991). In fact, virtually all forms of protein cytopathology seen in the ALS rats described here are evident in human ALS spinal cord, including deposits of SOD1 protein itself (Shibata et al., 1993), excessive phosphorylation of neurofilaments (Mizusawa et al., 1989; Sobue et al., 1990), and deposition of ubiquitin-positive bodies (Leigh et al., 1988, 1991; Matsumoto et al., 1993). Particularly in the H46R-4 rats, there were abundant intracytoplasmic Lewy-like bodies; these are also described in both the ALS mice (Bruijn et al., 1997) and human ALS tissues (Shibata et al., 1994, 1996). The importance of submicroscopic aggregates of SOD1 protein has been emphasized recently by reports that the mutant protein forms dimers and trimers even in the early phases of the illness in ALS mice (Johnston et al., 2000). It is underscored by reports that elimination of the protein CCS that delivers copper to the SOD1 molecule does not substantially alter the phenotype of ALS in transgenic G37R, G85R, and G93A mice (Cleveland and Liu, 2000).

Particularly striking in our data are not only the earlier onset of paralysis in the G93A-39 disease but also the much more rapid course $(8 \mathrm{~d})$ in this line as compared with the H46R-4 (24 d) rats. We do not understand the basis for this difference in rate of disease progression, but we note those factors determining the time course in these rats are likely to be relevant to human SOD1-mediated familial ALS. The human H46R cases also progress very slowly, with a mean survival of $16.8 \pm 6.8$ years (Aoki et al., 1993, 1994). By contrast, the mean survival of the G93A cases in one report was $2.2 \pm 1.5$ years (Cudkowicz et al., 1997). Although it is tempting to speculate that this shorter disease duration is a consequence of the higher retained dismutation activity in the G93A-39 line, we cannot firmly conclude this. We note, for example, that the fastest time course among the several lines of transgenic ALS mice is observed in the G86R animals (Ripps et al., 1995). The survival of these animals is $\sim 1$ week; yet, like the G85R counterparts, the G86R mice do not have elevated levels of dismutation activity.

Like human ALS and mouse transgenic ALS, our ALS rats developed a disease that shows a remarkable degree of motor neuron specificity. Although it is true that cell types other than neurons are affected, the phenotype is overwhelmingly attributable to motor neuron death. This is not simply a consequence of higher levels of expression of the mutant SOD1 transgene in spinal cord. In fact, our immunoblots of multiple tissues from an H46R-4 rat (Fig. 1d) reveal that, if anything, the level of expression of the transgene is greater in cerebellum than spinal cord, yet there is no clinical or pathological evidence of cerebellar disease in these rats.

There has been controversy in the literature of human ALS regarding levels of the excitatory amino acid glutamate in the CSF. Two studies have reported that glutamate levels are not elevated in the CSF of ALS patients (Perry et al., 1990; Camu et al., 1993), whereas a third study described increased glutamate concentrations in ALS CSF (Rothstein et al., 1990). Our data are 

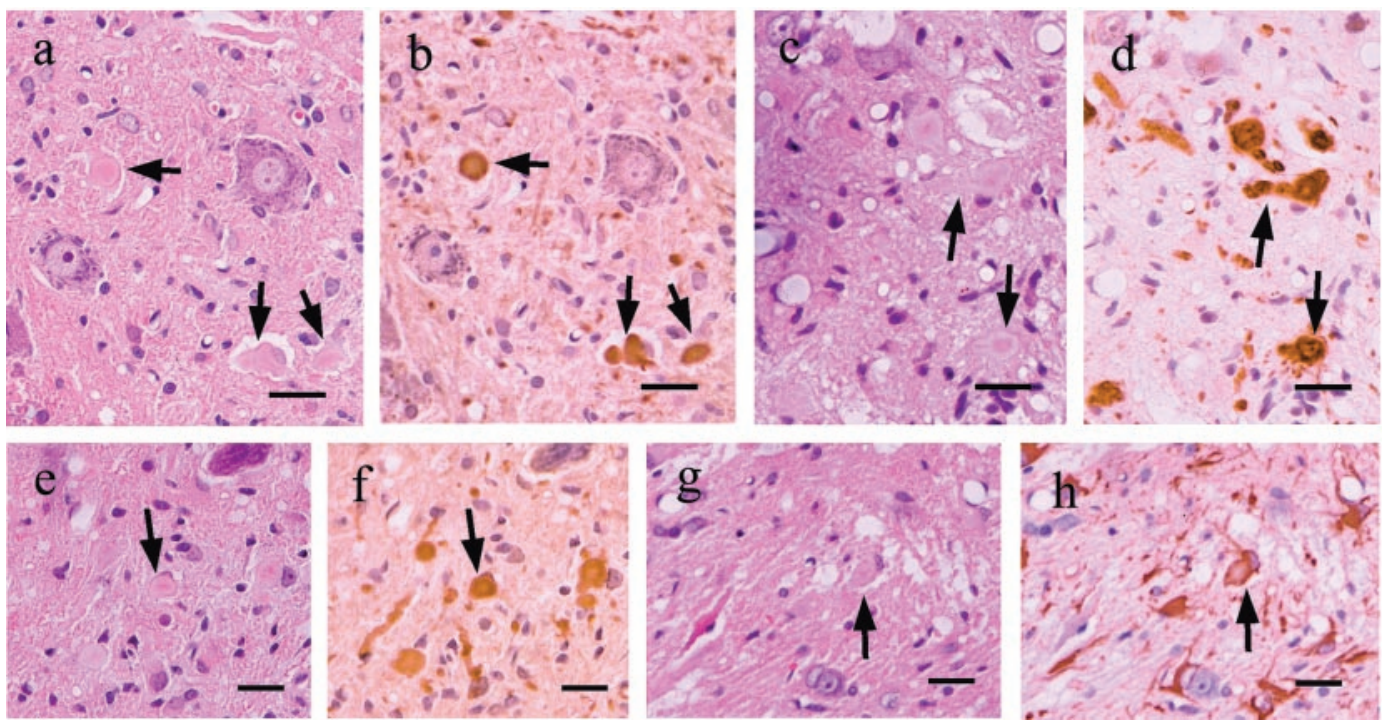

Figure 4. Intracellular inclusions in the 6-month-old H46R-4 transgenic rats. $a-d$, Lewy body-like cytoplasmic inclusions (arrows) in neuropil and in motor neurons. Inclusions consist of a pale periphery and dense central core as stained by hematoxylin and eosin $(a, c)$. Destaining $(a, c)$ and restaining $(b, d)$ of the same section with anti-human SOD1 antibody $(b)$ and anti-ubiquitin antibody $(d)$ demonstrated that these inclusions are immunoreactive for human SOD1 and ubiquitin. $e-h$, Lewy body-like cytoplasmic inclusions in astrocytes. Inclusions stained by hematoxylin and eosin $(e, g)$ have clear periphery and dense core like those in the neurons and the neuropil. Destaining $(e, f)$ and restaining $(g, h)$ of the same section revealed that inclusions are immunostained by the anti-human SOD1 antibody $(f)$ but not by anti-GFAP antibodies $(h)$, although the cell itself is GFAP-positive $(h)$. Scale bars, $40 \mu \mathrm{m}$.

a

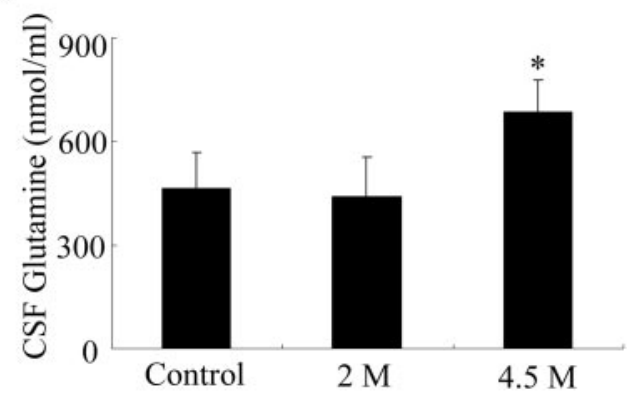

$\mathrm{b}$

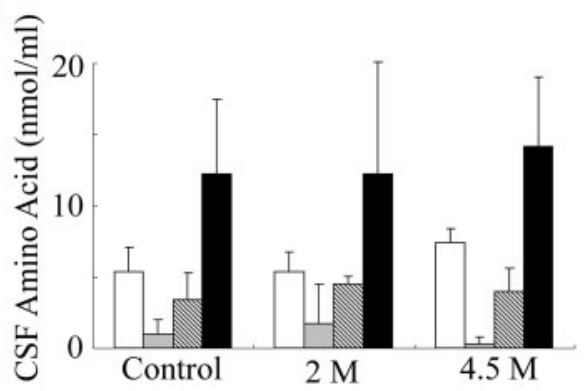

Figure 5. Amino acid levels in CSF from 2-month-old and end stage G93A-39 transgenic rats. $a$, Mean glutamine concentrations in CSF from 2-month-old and end stage transgenic rats and control littermates. ${ }^{*} p<$ 0.05 . $b$, Mean concentrations of asparagine (solid bar), aspartate (shaded bar), glutamate (hatched bar), and glycine (open bar) in CSF from 2-month-old and end stage transgenic rats and control littermates. The error bars denote the SD.

in accord with the former reports, because we have found that glutamate is not elevated in the CSF of our ALS rats (G93A-39) in either the presymptomatic ( 2 month) or end stages ( 4.5 month) of the disease. We note that those investigators also described an a
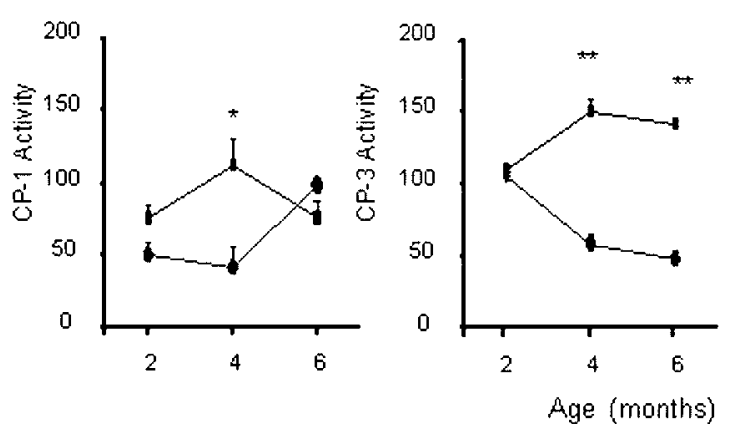

Figure 6. Caspase-1 and -3 are sequentially activated in the spinal cord of ALS transgenic rats. $a$, Caspase-1-like activity was measured as described and is reported as fluorescence emitted by the free AMC after cleavage of the caspase- 1 substrate YVAD-AMC. $b$, DEVD-AMC cleavage was measured to determine caspase-3 activity in spinal cord lysates of the ALS rats and their littermate controls. Caspase-3 activity is expressed as fluorescence emitted from the free fluorogenic group AMC. Data are the mean $\pm \mathrm{SD}$ for experiments assayed in duplicate. Asterisks $\left({ }^{*} p<0.05\right.$; $\left.{ }^{* *} p<0.01\right)$ indicate significant differences with respect to the control groups. Squares and diamonds indicate data derived from H46R-4 and control rats, respectively. Ages are in months.

increase in glutamine levels in ALS CSF (Perry et al., 1990; Camu et al., 1993), also in agreement with our data. The failure to detect a macroscopic elevation of glutamate in the CSF of these ALS transgenic rats by no means precludes a role for elevated synaptic glutamate in the pathogenesis of this disease. Indeed, on the basis of the totality of the evidence in the ALS mice, such a role for glutamate seems almost inescapable, at least as a secondary factor (Shaw and Ince, 1997). We are not entirely certain how to interpret the increase in CSF glutamine levels. We suspect that this reflects the ongoing astrogliosis in the spinal cord in these rats, because glutamine is found predominantly in astro- 
cytes, where it can be interconverted to glutamate. In another neurodegenerative disorder, Alzheimer's disease, the enzyme glutamine synthetase, which normally catalyzes glutamine formation, is elevated (Tzika et al., 1993). We note that in a recent study of ALS patients using magnetic resonance imaging spectroscopy, medullary levels of total glutamine and glutamate were increased (Pioro et al., 1999). The increase was speculatively ascribed to glutamate, but the authors could not exclude an increase in glutamine as well (Pioro et al., 1999).

Recent studies of ALS mice indicate that a common adverse effect of mutant SOD1 is the sequential activation of caspase-1 and -3 . This proteolytic cascade is shared by SOD1 mutants that provoke quite diverse pathologies in the various ALS mouse models (Li et al., 2000; Pasinelli et al., 1998, 2000; Vukosavic et al., 2000). Our data confirm and further extend those findings. We now show the same sequential proteolytic cascade in the H46R rats that develop the disease from a mutant protein with properties remarkably different from the other mutations. This implies that caspase activation is related to the expression of the mutant protein itself and not to variations in SOD1 activity. Together with the previous findings in the ALS mice, our data indicate that caspase activation is a consistent feature in the neurodegenerative process mediated by mutant SOD1. Even if not sufficient to stop the disease, caspase inhibition may be a valuable target for new therapies in ALS.

A transgenic rat model of human ALS will offer several advantages with respect to the existing transgenic mouse ALS models. Given its larger size, it will facilitate all studies that entail CSF analysis and, in particular, those that entail multiple, serial manipulations of CSF in the same animal. Thus, as illustrated in our analysis of glutamate and glutamine, it will be possible in this model to obtain adequate CSF for conventional biochemical studies as well as analyses of small molecules and even DNA/ RNA species that may distinguish the ALS from the wild-type CSF. Moreover, this model should be ideal for administration of therapies via chronic intrathecal pumps, a strategy that has been used recently in human ALS clinical trials. Another advantage of the ALS rats is that they can tolerate some forms of immunosuppressive therapy that are problematic in mice, such as cyclosporine A. This point arises in the context of an emerging interest in possible strategies to use implanted neural stem cells as therapy in ALS. It should now be possible to achieve appropriate immunosuppression in the ALS rats to allow survival of implanted cells and hence determine the efficacy of this approach. As a corollary, we also note that the larger size of the rat spinal cord will facilitate delivery of cells to the target spinal cord regions.

\section{REFERENCES}

Aoki M, Ogasawara M, Matsubara Y, Narisawa K, Nakamura S, Itoyama Y, Abe K (1993) Mild ALS in Japan associated with novel SOD mutation. Nat Genet 5:323-324.

Aoki M, Ogasawara M, Matsubara Y, Narisawa K, Nakamura S, Itoyama Y, Abe K (1994) Familial amyotrophic lateral sclerosis (ALS) in Japan associated with $\mathrm{H} 46 \mathrm{R}$ mutation in $\mathrm{Cu} / \mathrm{Zn}$ superoxide dismutase gene: a possible new subtype of familial ALS. J Neurol Sci 126:77-83.

Beauchamp C, Fridovich I (1971) Superoxide dismutase: improved assays and an assay applicable to acrylamide gels. Anal Biochem 44:276-287.

Borchelt DR, Lee MK, Slunt HS, Guarnieri M, Xu ZS, Wong PC, Brown RHJ, Price DL, Sisodia SS, Cleveland DW (1994) Superoxide dismutase 1 with mutations linked to familial amyotrophic lateral sclerosis possesses significant activity. Proc Natl Acad Sci USA 91:8292-8296.

Brown RHJ (1995) Amyotrophic lateral sclerosis: recent insights from genetics and transgenic mice. Cell 80:687-692.

Brownell B, Oppenheimer DR, Hughes JT (1970) The central nervous system in motor neurone disease. J Neurol Neurosurg Psychiatry $33: 338-357$.
Bruijn L, Becher M, Lee M, Anderson K, Jenkins N, Copeland N, Sisodia S, Rothstein J, Borchelt D, Price D, Cleveland D (1997) ALS-linked SOD1 mutant G85R mediates damage to astrocytes and promotes rapidly progressive disease with SOD1-containing inclusion. Neuron 18:327-338

Camu W, Billiard M, Baldy-Moulinier M (1993) Fasting plasma and CSF amino acid levels in amyotrophic lateral sclerosis: a subtype analysis. Acta Neurol Scand 88:51-55.

Cleveland D, Liu J (2000) Oxidation versus aggregation: how do SOD1 mutants cause ALS? Nat Med 6:1320-1321.

Cleveland DW (1999) From Charcot to SOD1: mechanisms of selective motor neuron death in ALS. Neuron 24:515-520.

Cudkowicz M, McKenna-Yasek D, Sapp P, Chin W, Geller B, Hayden D, Horvtiz H, Brown R (1997) Epidemiology of SOD1 mutations in amyotrophic lateral sclerosis. Ann Neurol 41:210-212.

Elroy-Stein O, Bernstein Y, Groner Y (1986) Overproduction of human $\mathrm{Cu} / \mathrm{Zn}$-superoxide dismutase in transfected cells: extenuation of paraquat-mediated cytotoxicity and enhancement of lipid peroxidation. EMBO J 5:615-622.

Fleming TR, Lin DY (2000) Survival analysis in clinical trials: past developments and future directions. Biometrics 56:971-983.

Fridovich I (1986) Superoxide dismutases. Adv Enzymol 58:61-97.

Gurney ME, Pu H, Chiu AY, Dal Canto MC, Polchow CY, Alexander DD, Caliendo J, Hentati A, Kwon YW, Deng H-X, Chen W, Zhai P, Sufit RL, Siddique T (1994) Motor neuron degeneration in mice that express a human $\mathrm{Cu}, \mathrm{Zn}$ superoxide dismutase mutation. Science 264:1772-1775

Gurney ME, Cutting FB, Zhai P, Doble A, Taylor CP, Andrus PK, Hall ED (1996) Benefit of vitamin E, riluzole, and gabapentin in a transgenic model of familial amyotrophic lateral sclerosis. Ann Neurol 39:147-157.

Gurney ME, Tomasselli AG, Heinrikson RL (2000) Stay the executioner's hand. Science 288:283-284.

Hall ED, Oostveen JA, Gurney ME (1998) Relationship of microglial and astrocytic activation to disease onset and progression in a transgenic model of familial ALS. Glia 23:249-256.

Hashimoto-Gotoh T, Yasojima K, Tsujimura A (1995) Plasmids with a kanamycin-resistance gene for site-directed mutagenesis using the oligodeoxyribonucleotide-directed dual amber method. Gene 167:333-334.

Hirano A (1991) Cytopathology in amyotrophic lateral sclerosis. Adv Neurol 56:91-101.

Hirano A, Kurland L, Sayre G (1967) Familial amyotrophic lateral sclerosis. A subgroup characterized by posterior and spinocerebellar tract involvement and hyaline inclusions in the anterior horn cells. Arch Neurol 16:232-243.

Hochi S, Ninomiya T, Honma M, Yuki A (1990) Successful production of transgenic rats. Animal Biotech 1:174-185.

Ioannou PA, Amemiya CT, Garnes J, Kroisel PM, Shizuya H, Chen C, Batzer MA, de Jong PJ (1994) A new bacteriophage P1-derived vector for the propagation of large human DNA fragments. Nat Genet 6:84-89.

Jaarsma D, Haasdijk ED, Grashorn JA, Hawkins R, van Duijn W, Verspaget HW, London J, Holstege JC (2000) Human Cu/Zn superoxide dismutase (SOD1) overexpression in mice causes mitochondrial vacuolization, axonal degeneration, and premature motoneuron death and accelerates motoneuron disease in mice expressing a familial amyotrophic lateral sclerosis mutant SOD1. Neurobiol Dis 7:623-643.

Johnston JA, Dalton MJ, Gurney ME, Kopito RR (2000) Formation of high molecular weight complexes of mutant $\mathrm{Cu}, \mathrm{Zn}$-superoxide dismutase in a mouse model for familial amyotrophic lateral sclerosis. Proc Natl Acad Sci USA 97:12571-12576.

Leigh PN, Anderton BH, Dodson A, Gallo JM, Swash M, Power DM (1988) Ubiquitin deposits in anterior horn cells in motor neurone disease. Neurosci Lett 93:197-203.

Leigh PN, Whitwell H, Garofalo O, Buller J, Swash M, Martin JE, Gallo JM, Weller RO, Anderton BH (1991) Ubiquitin-immunoreactive intraneuronal inclusions in amyotrophic lateral sclerosis. Morphology, distribution, and specificity. Brain 114:775-788.

Levanon D, Lieman-Hurwitz J, Dafni N, Wigderson M, Sherman L, Bernstein Y, Laver-Rudich Z, Danciger E, Stein O, Groner Y (1985) Architecture and anatomy of the chromosomal locus in human chromosome 21 encoding the $\mathrm{Cu} / \mathrm{Zn}$ superoxide dismutase. EMBO J 4:77-84

Li M, Ona VO, Guegan C, Chen M, Jackson-Lewis V, Andrews LJ, Olszewski AJ, Stieg PE, Lee JP, Przedborski S, Friedlander RM (2000) Functional role of caspase-1 and caspase-3 in an ALS transgenic mouse model. Science 288:335-339.

Matsumoto S, Goto S, Kusaka H, Imai T, Murakami N, Hashizume Y, Okazaki H, Hirano A (1993) Ubiquitin-positive inclusion in anterior horn cells in subgroups of motor neuron diseases: a comparative study of adult-onset amyotrophic lateral sclerosis, juvenile amyotrophic lateral sclerosis and Werdnig- Hoffmann disease. J Neurol Sci 115:208-213.

Mizusawa H, Matsumoto S, Yen SH, Hirano A, Rojas-Corona RR, 
Donnenfeld H (1989) Focal accumulation of phosphorylated neurofilaments within anterior horn cell in familial amyotrophic lateral sclerosis. Acta Neuropathol (Berl) 79:37-43.

Mulder D, Kurland L, Offord K, Beard C (1986) Familial adult motor neuron disease: amyotrophic lateral sclerosis. Neurology 36:511-517.

Parge HE, Hallewell RA, Tainer JA (1992) Atomic structures of wildtype and thermostable mutant recombinant human $\mathrm{Cu}, \mathrm{Zn}$ superoxide dismutase. Proc Natl Acad Sci USA 89:6109-6113.

Pasinelli P, Borchelt DR, Houseweart MK, Cleveland DW, Brown Jr RH (1998) Caspase-1 is activated in neural cells and tissue with amyotrophic lateral sclerosis-associated mutations in copper-zinc superoxide dismutase. Proc Natl Acad Sci USA 95:15763-15768.

Pasinelli P, Houseweart MK, Brown Jr RH, Cleveland DW (2000) Caspase- 1 and -3 are sequentially activated in motor neuron death in $\mathrm{Cu}, \mathrm{Zn}$ superoxide dismutase-mediated familial amyotrophic lateral sclerosis. Proc Natl Acad Sci USA 97:13901-13906.

Perry TL, Krieger C, Hansen S, Eisen A (1990) Amyotrophic lateral sclerosis: amino acid levels in plasma and cerebrospinal fluid. Ann Neurol 28:12-17.

Pioro EP, Majors AW, Mitsumoto H, Nelson DR, Ng TC (1999) 1HMRS evidence of neurodegeneration and excess glutamate + glutamine in ALS medulla. Neurology 53:71-79.

Reaume A, Elliott J, Hoffman E, Kowall N, Ferrante R, Siwek D, Wilcox H, Flood D, Beal M, Brown R, Scott R, Snyder W (1996) Motor neurons in $\mathrm{Cu} / \mathrm{Zn}$ superoxide dismutase-deficient mice develop normally but exhibit enhanced cell death after axonal injury. Nat Genet 13:43-47.

Ripps ME, Huntley GW, Hof PR, Morrison JH, Gordon JW (1995) Transgenic mice expressing an altered murine superoxide dismutase gene provide an animal model of amyotrophic lateral sclerosis. Proc Natl Acad Sci USA 92:689-693.

Rosen DR, Siddique T, Patterson D, Figlewicz DA, Sapp P, Hentati A, Donaldson D, Goto J, O'Regan JP, Deng HX, Rahmani Z, Krizus A, McKenna-Yasek D, Cayabyab A, Gaston SM, Berger R, Tanzi RE, Halperin JJ, Herzfeldt B, Van den Bergh R, Hung WY, Bird T, Deng G, Mulder DW, Smyth C, Laing NG, Soriano E, Pericak-Vance M, Haines J, Rouleau GA, Gusella GS, Horvitz HR, Brown RHJ (1993) Mutations in $\mathrm{Cu} / \mathrm{Zn}$ superoxide dismutase gene are associated with familial amyotrophic lateral sclerosis. Nature 362:59-62.
Rothstein JD, Tsai GT, Kuncl RW, Clawson L, Cornblath DR, Drachman DB, Pestronk A, Stauch BL, Coyle JT (1990) Abnormal excitatory amino acid metabolism in amyotrophic lateral sclerosis. Ann Neurol 28: $18-25$.

Shaw PJ, Ince PG (1997) Glutamate, excitotoxicity and amyotrophic lateral sclerosis. J Neurol 244[Suppl 2]:S3-14.

Shibata N, Hirano A, Kobayashi A, Asayama K, Umahara T, Komori T, Ikemoto A (1993) Immunohistochemical demonstration of $\mathrm{Cu} / \mathrm{Zn}$ superoxide dismutase in the spinal cord of patients with familial amyotrophic lateral sclerosis. Acta Histochem Cytochem 26:619-622.

Shibata N, Hirano A, Kobayashi M, Sasaki S, Kato K, Matsumoto S, Shiozawa Z, Komori T, Ikemoto A, Umahara T, Asayama K (1994) $\mathrm{Cu} / \mathrm{Zn}$ superoxide dismutase-like immunoreactivity in Lewy body-like inclusions of sporadic amyotrophic lateral sclerosis. Neurosci Lett 179:149-152.

Shibata N, Hirano A, Kobayashi M, Siddique T, Deng H-X, Hung W-Y, Kato T, Asayama K (1996) Intense superoxide dismutase-1 immunoreactivity in intracytoplasmic hyaline inclusions of familial amyotrophic lateral sclerosis with posterior column involvement. J Neuropathol Exp Neurol 4:481-490.

Sobue G, Hashizume Y, Yasuda T, Mukai E, Kumagai T, Mitsuma T, Trojanowski JQ (1990) Phosphorylated high molecular weight neurofilament protein in lower motor neurons in amyotrophic lateral sclerosis and other neurodegenerative diseases involving ventral horn cells. Acta Neuropathol (Berl) 79:402-408.

Tzika AA, Vigneron DB, Ball WS, Dunn RS, Kirks DR (1993) Localized proton MR spectroscopy of the brain in children. J Magn Reson Imaging 3:719-729.

Vukosavic S, Stefanis L, Jackson-Lewis V, Guegan C, Romero N, Chen C, Dubois-Dauphin M, Przedborski S (2000) Delaying caspase activation by Bcl-2: a clue to disease retardation in a transgenic mouse model of amyotrophic lateral sclerosis. J Neurosci 20:9119-9125.

Wong P, Pardo C, Borchelt D, Lee M, Copeland N, Jenkins N, Sisodia S, Cleveland D, Price D (1995) An adverse property of a familial ALS linked SOD1 mutation causes motor neuron disease characterized by vacuolar degeneration of mitochondria. Neuron 14:1105-1116.

Yamada N, Shimoda K, Takahashi K, Takahashi S (1986) Change in period of free-running rhythms determined by two different tools in blinded rats. Physiol Behav 36:357-362. 